\title{
Glass formation in a multicomponent Zr-based alloy by mechanical attrition and liquid undercooling
}

\author{
A. Sagel, R. K. Wunderlich, J. H. Perepezko, a) and H.-J. Fecht ${ }^{\text {b) }}$ \\ Institute of Metal Physics and Technology, Technical University Berlin, D-10623 Berlin, Germany
}

(Received 15 October 1996; accepted for publication 26 November 1996)

\begin{abstract}
The synthesis of a multicomponent $\mathrm{Zr}_{60} \mathrm{Al}_{10} \mathrm{Ni}_{9} \mathrm{Cu}_{18} \mathrm{Co}_{3}$ glass by mechanical alloying has been investigated using thermal and structural analysis and compared with a metallic glass produced by liquid undercooling. The solid-state amorphization reaction is preceded by rapid solution of smaller solute atoms in the $\mathrm{Zr}$ matrix with a concomitant reduction in grain size to $10 \mathrm{~nm}$ at the amorphization onset. A fully amorphous mechanically alloyed sample shows relaxation compared to a sample synthesized by liquid cooling probably due to removal of residual inhomogeneities on the scale of the nanocrystal size at amorphization. While the kinetic pathways for the two synthesis methods differ, the relaxed amorphous phases from each method exhibit identical thermodynamic properties. () 1997 American Institute of Physics. [S0003-6951(97)01705-1]
\end{abstract}

Glasses can be obtained by several routes including (i) incorporating static disorder into a crystalline phase mixture through solid-state processes or (ii) freezing in dynamic disorder through sufficient undercooling of the liquid at a composition outside the polymorphous melting temperature $T_{0}{ }^{1}{ }^{1}$ The equivalence of the amorphous state achieved by the two pathways is of interest in terms of the evolution of the amorphization (am) processes. This issue is addressed in the present study by examining the structural and thermal properties of a multicomponent $\mathrm{Zr}_{60} \mathrm{Al}_{10} \mathrm{Ni}_{9} \mathrm{Cu}_{18} \mathrm{Co}_{3}$ glass, which is representative of a wider class of new alloys. ${ }^{2}$ Multicomponent $\mathrm{Zr}$-based alloys have recently been shown to produce bulk glassy metals at liquid cooling rates as low as $1-500$ $\mathrm{K} / \mathrm{s} .{ }^{3,4}$ While all of the factors responsible for the easy glass formation have not been fully identified, it is evident that multicomponent interactions can be important. ${ }^{5,6}$ In the present work, powder samples synthesized by mechanical alloying (MA) are compared with liquid-quenched samples of the same composition.

Elemental powders of $99.99 \%$ purity with the composition $\mathrm{Zr}_{60} \mathrm{Al}_{10} \mathrm{Ni}_{9} \mathrm{Cu}_{18} \mathrm{Co}_{3}$ were mechanically alloyed under a high purity Ar atmosphere in a Spex ball mill with a powderto-ball ratio of $6: 1 .^{7}$ After $36 \mathrm{~h}$ of ball milling, the oxygen and the Fe content were determined by EDX to be approximately 1 at. \%. Liquid-quenched samples with about $50 \mu \mathrm{m}$ thickness were also produced in a splat quenching device. $\mathrm{X}$-ray diffraction spectra (XRD) were obtained with an Enraf Nonius goniometer with a large-angle position sensitive detector (Inel CPS 120). Thermal analysis was performed with a Perkin Elmer DSC-7 in Al pans under purified Ar atmosphere. Temperature and specific heat calibrations were carried out with melting point and heat of fusion of indium and zinc.

The XRD spectra taken at different stages of the milling process are characterized by the disappearance of the elemental $\mathrm{Ni}, \mathrm{Co}, \mathrm{Cu}$, and $\mathrm{Al}$ peaks and a shift in the $\mathrm{Zr}$ (101) peak to higher $2 \Theta$ values in Fig. 1(a). From observations on

\footnotetext{
${ }^{a)}$ Permanent address: Department of Materials Science and Engineering, University of Wisconsin-Madison, 1509 University Avenue, Madison, WI 53706.

b)Electronic mail: fecht@emmi.physik.tu-berlin.de
}

binary powder mixtures, ${ }^{7,8}$ this is indicative of the subsequent dissolution of $\mathrm{Ni}, \mathrm{Cu}, \mathrm{Co}$, and $\mathrm{Al}$ in the $\mathrm{Zr}$ matrix with a concomitant shrinkage of the hcp lattice. Figure 1(a) shows, in addition, the average $\mathrm{Zr}$ grain diameter as evaluated with the Scherrer formula based on the $\mathrm{Zr}$ (101) peak. The final grain size of $10 \mathrm{~nm}$ is reached after $5 \mathrm{~h}$ milling time. After $7 \mathrm{~h}$ milling time, a broad background in the XRD spectra indicates the onset of amorphous phase formation.

The appearance of the broad am halo in the XRD spectra is correlated clearly with the observation of a glass transition in a differential scanning calorimetry (DSC) trace. The final product of the am reaction in the multicomponent powder is established by the constancy of structural measures such as the $2 \Theta$ position and width of the am halo together with thermal characteristics such as the glass transition temperature $T_{g}$, height of endothermic step at $T_{g}$, width of the glass transition $\delta T_{g}$, defined as the difference between the onset

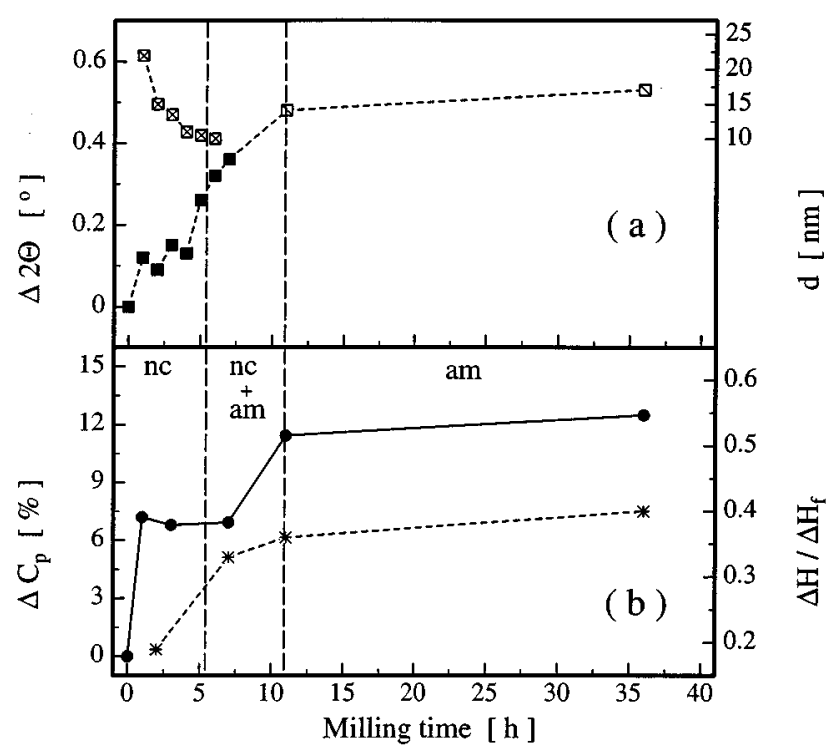

FIG. 1. (a) Grain diameter of $\operatorname{Zr}(\otimes)$ and shift in the $2 \Theta$ position of the hcp $\mathrm{Zr}(101)$ peak $(\square)$ and of the first am halo $(\nabla)$ as a function of milling time. (b) Change in the specific heat $C_{p}-C_{p}^{\text {ideal }} / C_{p}^{\text {ideal }}=\Delta C_{p}$ of powder specimen (-) and integrated heat release $\Delta H(*)$ normalized to the latent heat, $\Delta H_{f}$, as a function of milling time. 


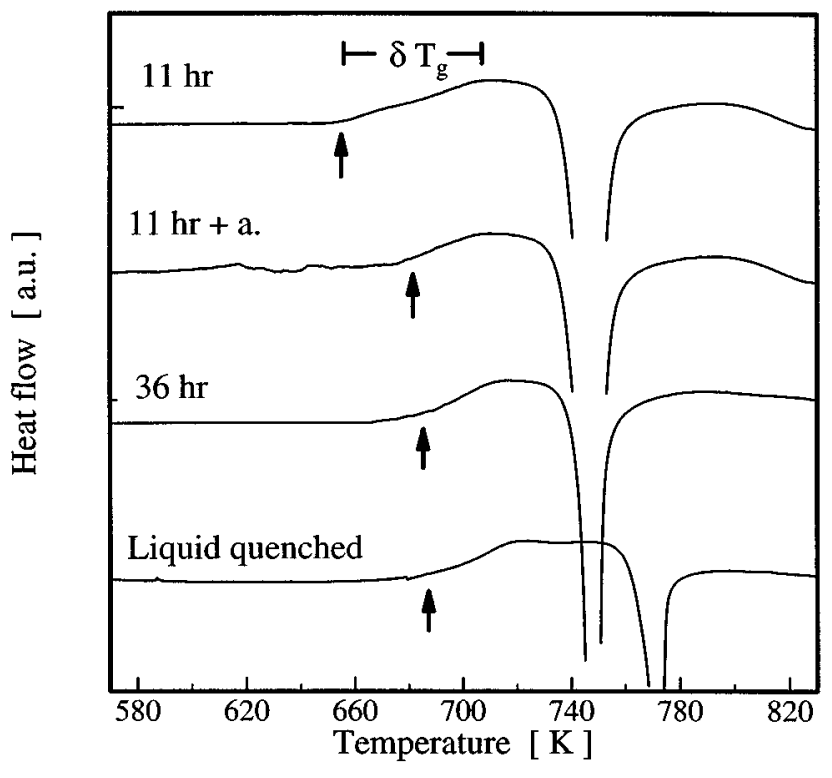

FIG. 2. DSC traces of $11 \mathrm{~h}, 11 \mathrm{~h}+$ annealed, $36 \mathrm{~h}$ mechanically milled samples, and rapidly quenched splat with a heating rate of $10 \mathrm{~K} / \mathrm{min}$.

and the maximum of glass transition as shown in Fig. 2, and the crystallization enthalpy at a given heating rate. DSC thermograms from powder specimens after 11 and $36 \mathrm{~h}$ milling time and from a liquid-quenched alloy are given in Fig. 2 and show a similar $T_{g}$ between the $36 \mathrm{~h}$ milled specimen and the liquid-quenched glass for a heating rate of $10 \mathrm{~K} / \mathrm{min}$. Moreover, XRD spectra do not reveal any structural difference indicating the similarity of the amorphous state of the powder and the liquid quenched specimen with regard to the above criteria.

In order to investigate further the evolution of the am phase, DSC measurements were performed at different stages of the milling process. Figure 1(b) shows the change in specific heat $\Delta C_{p}$ at $320 \mathrm{~K}$ of the powder specimen as compared to an ideal solution of the pure elements and the integrated exothermic heat release $\Delta H$ up to $870 \mathrm{~K}$ normalized to the latent heat, $\Delta H_{f}$, as a function of milling time. The overall dependence of $\Delta C_{p}$ and $\Delta H / \Delta H_{f}$ on milling time correlates well with that of the $\mathrm{Zr}$ (101) peak position in Fig. 1(a). The first increase of $7 \%$ in $C_{p}$ for milling times 0-3 $\mathrm{h}$ is mainly the result of the intermixing reaction of the fast moving alloy species ${ }^{9}$ with the $\mathrm{Zr}$ matrix together with a possible small contribution from the formation of grain boundaries in the nanoscaled structure. For milling times $<10 \mathrm{~h}$ the enthalpy release consists of contributions due to grain growth as well as the amorphization reaction. ${ }^{10}$ The second break in the $C_{p}$ increase after a milling time of $8 \mathrm{~h}$ is correlated with the onset of the amorphization reaction. For milling times $>11 \mathrm{~h}$ the final value of the $C_{p}$ increase at $12 \%$ is similar to the observations made on binary $\mathrm{Zr}-\mathrm{Al}$ alloys. ${ }^{7}$ This is in accordance with measurements of the total released enthalpy showing a fraction of the am phase $>92 \%$ for $11 \mathrm{~h}$ milling time as compared with the final am specimen after $36 \mathrm{~h}$ milling time where $\Delta H / \Delta H_{f}$ reaches 0.4 , similar to that of the liquid-quenched sample for the same heating rate.

The DSC thermograms in Fig. 2, taken with a heating

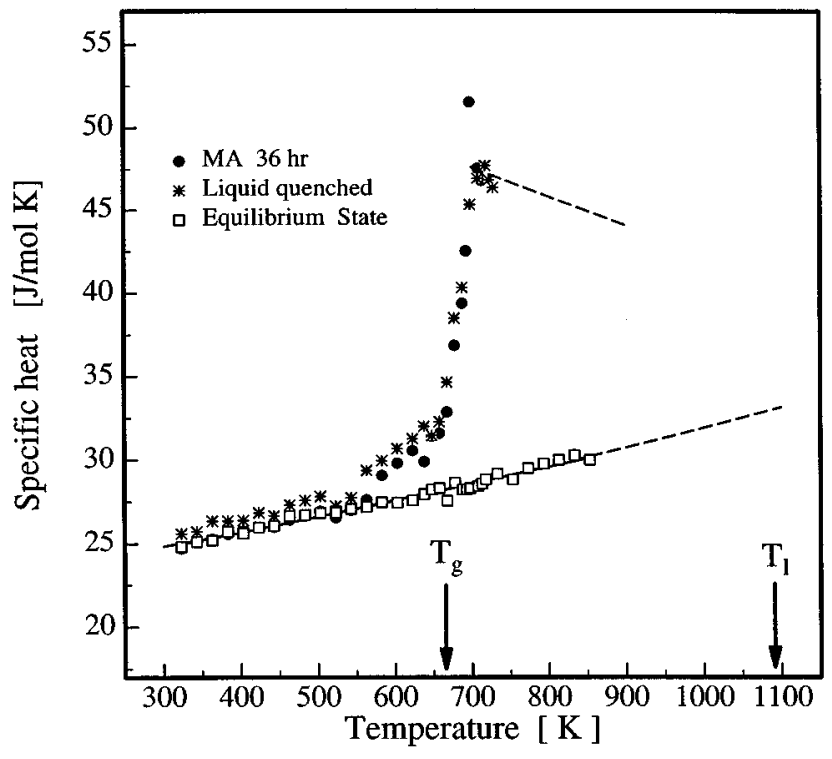

FIG. 3. Specific heat as a function of temperature of $36 \mathrm{~h}$ milled powder (O), liquid-quenched sample (*), and equilibrated sample ( $\square$ ). The milled powder and liquid-quenched samples are amorphous while the equilibrated sample is fully crystalline.

rate of $10 \mathrm{~K} / \mathrm{min}$, show an increase in $T_{g}$ as function of milling time from $650 \mathrm{~K}$ for the $11 \mathrm{~h}$ milled sample to $685 \mathrm{~K}$ for the final am phase. It is worthwhile noting that the $T_{g}$ of the $11 \mathrm{~h}$ milled sample is close to that for glassy binary $\mathrm{Zr}-\mathrm{Ni}$ alloys in the composition range $60-80$ at. $\% \mathrm{Zr}^{11}$ Moreover, the width of the glass transition $\delta T_{g}$ decreases as a function of milling time as demonstrated in Fig. 2. Usually, $\delta T_{g}$ is about $10-20 \mathrm{~K}$ for a given alloy composition. ${ }^{12}$ For a multicomponent alloy synthesized from elemental powders, separate local regions can enter the amorphous state at different compositions within the glass forming range and yield a broadened $\delta T_{g}$, which is about $40 \mathrm{~K}$ for the $11 \mathrm{~h}$ milled sample. Continued milling can serve to homogenize the sample to yield a narrowing of $\delta T_{g}$ and an increase in $T_{g}$ as supported by the $36 \mathrm{~h}$ milled sample. A similar effect on $\delta T_{g}$ and $T_{g}$ can be produced by thermal annealing as observed in the $11 \mathrm{~h}$ sample after annealing at $650 \mathrm{~K}$ in Fig. 2. This compositional relaxation effect on $T_{g}$ can be opposite to the usual structural relaxation induced by thermal annealing, which yields a lowering of $T_{g} \cdot{ }^{13}$

Temperature-dependent specific heat measurements, shown in Fig. 3, were performed with the $36 \mathrm{~h}$ milled powder, the splat-quenched alloy and a crystallized specimen (equilibrated at $873 \mathrm{~K}$ for four days). The powder and liquidquenched specimens were annealed at $\left(T_{g}-40 \mathrm{~K}\right)$ for $2 \mathrm{~h}$ for relaxation before measurement. At temperatures below $T_{g}$ the specific heats of both specimens agree very well and, in fact, coincide at $T_{g}$. As a further probe of the thermal stability and relaxation behavior of different pathways to the am state, continuous heating experiments are useful. For example, in Fig. 4 a kinetics analysis of the crystallization reaction in the liquid-quenched and the MA samples yields equivalent energetics with an activation energy of $3.6 \mathrm{eV}$. It is useful to note that, in this case, both Arrhenius and Kissinger plots ${ }^{14}$ [where $\ln$ (heating rate/ $T_{c}^{2}$ ) is plotted against $\left.1 / T_{c}\right]$ yield similar activation energies. This value is close to 


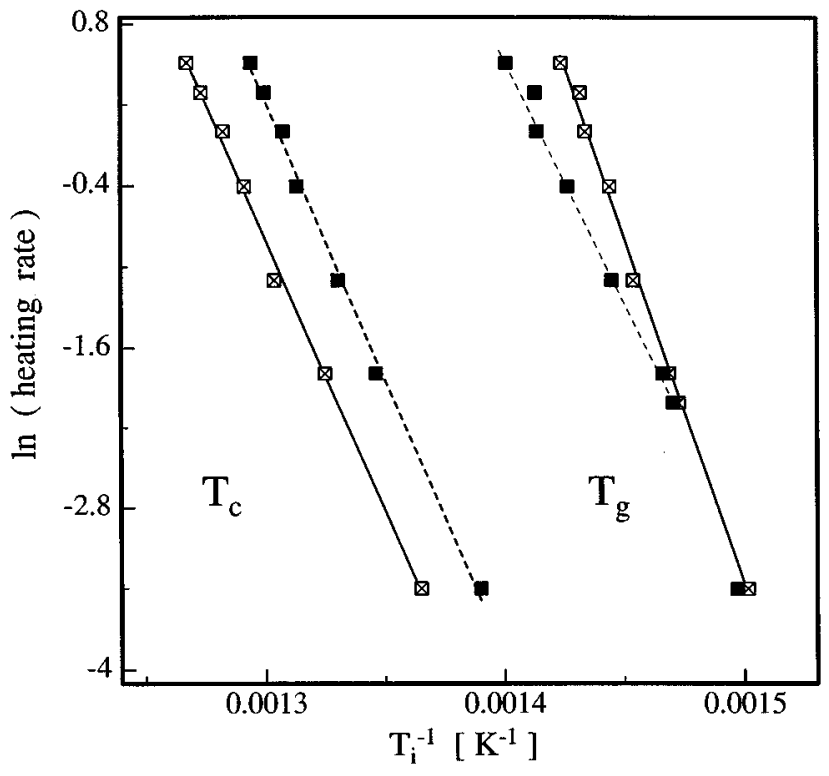

FIG. 4. Arrhenius plot for heating rate dependence of $T_{g}$ and $T_{c}$ for the 36 $\mathrm{h}$ milled powder $(\boldsymbol{\square})$ and liquid-quenched sample $(\otimes)$, unrelaxed.

that reported in binary $\mathrm{Zr}-\mathrm{Ni}$ glasses, ${ }^{11}$ implying that the diffusive processes for the long range solute partitioning involved in crystallization are similar. For the heating rate dependence of $T_{g}$ an Arrhenius plot is suitable for a limited range. ${ }^{12}$ From Fig. 4 there is a divergence in behavior above $10 \mathrm{~K} / \mathrm{min}$ that offers some insight into the characteristic relaxation scales. For example, for heating rates of $\leqslant 10$ $\mathrm{K} / \mathrm{min}$, the MA sample behavior merges with that for the liquid-quenched sample indicating a similar relaxation state. Indeed, at the merging point of $10 \mathrm{~K} / \mathrm{min}$, which corresponds to a characteristic time of about $10^{2} \mathrm{~s}$, the reported diffusivity in amorphous $\mathrm{Zr}-\mathrm{Al}-\mathrm{Cu}-\mathrm{Ni}$ alloys $\left(10^{-19}-10^{-20}\right.$ $\left.\mathrm{m}^{2} / \mathrm{s}\right)^{15}$ implies a diffusional distance comparable to the nearest-neighbor separation (i.e., $0.3 \mathrm{~nm}$ ). For heating ranges $>10 \mathrm{~K} / \mathrm{min}$, the relaxation scales of the samples diverge. From the activation energy of $3.7 \mathrm{eV}$ obtained from the MA sample data in Fig. 4 and reported prefactor, ${ }^{15}$ a diffusional scale of 7-9 $\mathrm{nm}$ is indicated for the MA sample with heating rates $10-100 \mathrm{~K} / \mathrm{min}$. It is interesting that this scale is comparable to the nanocrystal size at the onset of amorphization during MA, indicating that a residual inhomogeneity persists that can be relaxed by annealing. In fact, this has been confirmed by examining the heating rate dependence for a relaxed MA sample. Moreover, the size scale of mixing reflects the effectiveness of ball milling for alloying reactions since the dissolution of $30 \mu \mathrm{m}$ elemental powders in the $36 \mathrm{~h}$ MA samples indicates a "mechanically enhanced" diffusivity of at least $10^{-15} \mathrm{~m}^{2} / \mathrm{s}$. Lastly, it is also evident that for a continued decrease in the heating rate, the $T_{g}$ values will depart the trend in Fig. 4 and will asymptotically approach the ideal glass transition temperature that is evaluated as
$T_{0}=640 \mathrm{~K}$ based upon analysis of the measured enthalpies and specific heats for the alloy. The apparent structural deviation responsible for the diverging heating rate dependence of $T_{g}$ can not be clearly identified by standard XRD analysis, but does indicate that the states for the unrelaxed liquidquenched and am-powder samples as identified by $T_{g}$ above $10 \mathrm{~K} / \mathrm{min}$ and XRD are not fully equivalent.

In summary, the amorphous state in a $\mathrm{Zr}_{60} \mathrm{Al}_{10} \mathrm{Ni}_{9} \mathrm{Cu}_{18} \mathrm{Co}_{3}$ alloy has been synthesized by both mechanical alloying of elemental powders and liquid undercooling. Based upon standard XRD and thermal diagnostics (i.e., $2 \Theta$ peak position and $T_{g}$ ) the amorphous phase of the $36 \mathrm{~h}$ MA sample is similar to that for the liquid-quenched sample. Moreover, the enthalpy of crystallization from the undercooled liquid corresponds to about $40 \%$ of the enthalpy of fusion for both types of samples. However, relaxation kinetics measurements expose differences between the two sample types, which can be related to a residual inhomogeneity in the MA sample. In fact, during the alloying reaction that is induced by ball milling, the continued grain size refinement is one measure of the extent of reaction and the spatial extent of the mixing process that can be reflected in residual compositional inhomogeneities. Therefore, although the details of the respective pathways for the MA sample and liquid-quenched alloy are different, the relaxed amorphous phase for each case appears to be similar.

The financial support from the Deutsche Agentur für Raumfahrtangelegenheiten (DARA Grant No. 50 WM 9431-4), Deutsche Forschungsgemeinschaft (Grant No. Fe 313/ 6-2), and Alexander von Humboldt Foundation [Senior Research Award Fellowship for one of the authors (J.H.P.)], as well as helpful discussions with Professor A. L. Greer (Cambridge University) and Professor W. L. Johnson (Cal. Tech.) are gratefully acknowledged. The authors are most grateful to Professor K. Samwer (University of Augsburg) for help in providing the splats.

${ }^{1}$ H. J. Fecht and W. L. Johnson, Nature (London) 334, 50 (1988).

${ }^{2}$ A. Inoue, T. Zhang, and T. Masumoto, Mater. Trans. JIM 36, 391 (1995).

${ }^{3}$ A. Inoue, T. Zhang, and T. Masumoto, Mater. Trans. JIM 31, 17 (1990).

${ }^{4}$ A. Peker and W. L. Johnson, Appl. Phys. Lett. 63, 2342 (1993).

${ }^{5}$ T. Zhang, A. Inoue, and T. Masumoto, Mater. Trans. JIM 32, 1005 (1991).

${ }^{6}$ S. G. Klose, P. Frankwicz, and H. J. Fecht, Mater. Sci. Forum (in press).

${ }^{7}$ H. J. Fecht, G. Han, Z. Fu, and W. L. Johnson, J. Appl. Phys. 67, 1744 (1990).

${ }^{8}$ E. Ma and M. Atzmon, Phys. Rev. Lett. 67, 1126 (1991).

${ }^{9}$ R. B. Schwarz and W. L. Johnson, Phys. Rev. Lett. 51, 415 (1983).

${ }^{10}$ H. Schroeder, K. Samwer, and U. Köster, Phys. Rev. Lett. 54, 197 (1985).

${ }^{11}$ Z. Altounian, T. Guo-hua, and J. O. Strom-Olsen, J. Appl. Phys. 54, 3111 (1983).

${ }^{12}$ H. Baxi and T. B. Massalski, Mater. Sci. Eng. 97, 291 (1988).

${ }^{13}$ A. L. Greer, in Rapidly Solidified Alloys, Processes, Structures, Properties, Applications, edited by H. H. Liebermann (Marcel Dekker, New York, 1993), p. 269.

${ }^{14}$ H. E. Kissinger, Anal. Chem. 29, 1702 (1957).

${ }^{15}$ U. Köster, J. Meinhardt, S. Roos, and H. Liebertz, Appl. Phys. Lett. 69, 179 (1996). 